\title{
Utilizando a Placa de Som do Micro PC no Laboratório Didático de Física
}

\author{
Using the PC Sound Card in a Classroom Physics Laboratory \\ Rafael Haag \\ Instituto de Física, Universidade Federal do Rio Grande do Sul, \\ Caixa Postal 15051, 91501-970, Porto Alegre, RS, Brasil \\ E-mail: haag@if.ufrgs.br
}

Recebido em 03/01/2001. Aceito em 15/02/2001

\begin{abstract}
Descrevemos neste trabalho maneiras de utilizar a placa de som do PC como alternativa na aquisição de dados em um laboratório didático de física, dispensando a utilização de interfaces conversoras analógico-digitais internas ou externas. Uma experiência com um pêndulo físico ilustra a coleta de dados via porta joystyck. Explicamos como utilizar a entrada e saída de áudio e apresentamos uma coletânea de softwares livres disponíveis na rede que se valem destes recursos.
\end{abstract}

We report in the present work on the use of the sound card of a $\mathrm{PC}$ for data acquisition in a classroom physics laboratory, instead of using analogical-digital internal or external converters. A physical pendulum experiment illustrates data acquisition via the joystick port. We explain how to use the audio in an out entrances and present a collection of related softwares available freeware on the Web.

\section{Introdução}

Nos últimos anos diversos artigos foram publicados na Revista Brasileira de Ensino de Física sobre a aplicabilidade do microcomputador na aquisição de dados em laboratórios didáticos de física [1]-[7]. Alguns destes trabalhos são desenvolvidos com interfaces comerciais, as quais têm custos elevados [5]-[7]. Já em outros trabalhos, sugerem a construção de interfaces a serem acopladas à porta paralela do microcomputador [2]-[4]. Estas interfaces requerem a construção de circuitos eletrônicos que, embora não sejam complicados, exigem algum conhecimento de eletrônica para a sua manufatura, bem como algum custo econômico. Também em nível internacional tem sido proposto o uso de portas paralelas na aquisição de dados [8]-[13]. Neste trabalho apresentamos uma alternativa para aquisição de dados que dispensa uma interface conversora de sinais analógicos em digitais, visto que a aquisição é feita diretamente pela placa de som do microcomputador, que cumpre esta função. Como conseqüência, nossa proposta além de ser mais prática e economicamente menos dispendiosa, mantém a precisão requerida em laboratórios didáticos.

A necessidade de conversores analógico-digitais na aquisição de dados deve-se ao fato de que a maior parte das medidas físicas são analógicas (temperatura, corrente, voltagem, pressão,...), enquanto o computador processa as informações na forma digital, que é composta pelo alfabeto dos bits 0 (baixo) e 1 (alto). A placa de som é geralmente a única interface analógica presente em um microcomputador, podendo ser considerada como um conversor analógico/digital e digital/analógico disponível a baixo custo. Podemos considerá-la como uma interface entre o microcomputador PC e o mundo externo, cujo custo é da ordem de um décimo das interfaces comerciais desenvolvidas para tal fim.

Uma placa de som convencional possui uma entrada para joystick e suporte de MIDI, entrada de baixo nível, entrada de microfone e saída de áudio. A aquisição de dados através da entrada de joystick, também chamada de porta game, já foi proposta há alguns anos [1], mas injustificadamente parece ter sido relegada. Neste trabalho implementamos esta possibilidade para um sistema computacional atual ${ }^{1}$. Além disto, apresentamos a possibilidade de utilização da entrada e saída de áudio da placa de som na aquisição de dados. Embora haja softwares livres disponíveis na rede que se valem destes

\footnotetext{
${ }^{1}$ Aqui nos limitamos ao sistema operacional Windows. Sua implementação no sistema $L I N U X$ não apresenta dificuldade adicional e deverá ser feita brevemente.
} 
recursos [14]-[19], desconhecemos documentação pertinente ao assunto que introduza os conceitos básicos e permita que o próprio professor se valha desta possibilidade para o desenvolvimento de um sistema de coleta de dados. Comentaremos as características técnicas de funcionamento da placa de som e descreveremos uma simples experiência para determinação da amplitude de oscilação de um pêndulo em função do ângulo de oscilação. Com isto, deseja-se abrir uma nova janela para o ensino dentro do laboratório didático de física, que permita desenvolver novas experiências que caminham ao lado das novas tecnologias e dos conceitos fisicos a elas relacionados.

\section{Princípio de Funcionamento da Placa de Som do PC}

A seguir abordaremos as características técnicas relevantes da placa de som na aquisição de dados.

\section{II.1 Porta Joystick da Placa de Som}

São poucos os trabalhos a respeito da utilização da porta joystick [1] para aquisição de dados em experiências no laboratório de física. A porta joystick usa um conector do tipo DB15(fêmea) e está localizada na placa de som. Na figura 1, identificamos os pinos deste conector.

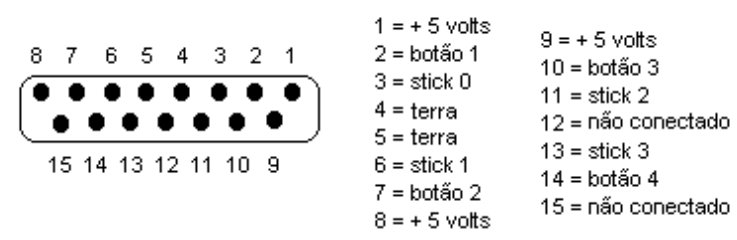

Figura 1. Diagrama de pinagem do conector de joystick DB15.

Nesta porta, temos quatro entradas (botões) que são utilizadas para receber informações digitais binárias (alto ou baixo) e quatro entradas (sticks) analógicas. A porta joystick para o computador é simplesmente uma porta de 8 bits que usa o endereço I/O 201h. A CPU do microcomputador lê e escreve os dados desta porta no endereço 201h. Os quatro primeiros bits indicam o estado lógico dos botões da porta joystick. Os últimos quatro bits mostram o estado dos multivibradores usados para medir o valor da corrente existente nas entradas analógicas da porta joystick. Esta corrente varia em função da resistência existente na entrada e também do resistor interno que encontra-se ligado em série com esta entrada. A diferença de potencial aplicada em cada entrada analógica é padronizada $(5 \mathrm{~V})$. A entrada analógica da porta joystick consiste de uma interface eletrônica composta basicamente por quatro multivibradores monoestáveis. Estes multivibradores são circuitos eletrônicos que produzem um pulso retangular cuja duração é diretamente proporcional à corrente existente na entrada. A duração deste pulso é então medida e armazenada usando uma rotina via software. Na figura 2, temos um circuito típico de uma destas entradas analógicas.

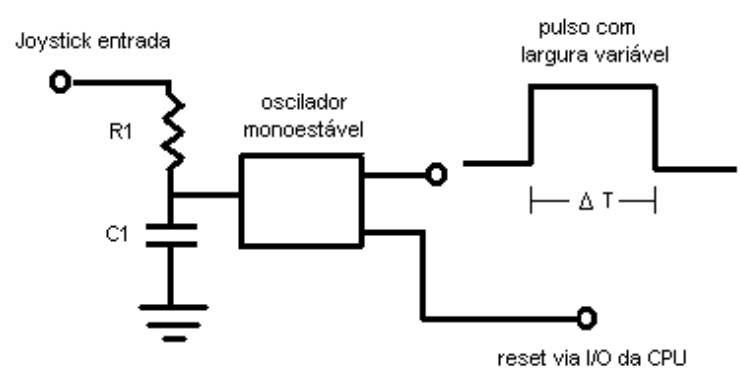

Figura 2. Diagrama simplificado do funcionamento dos multivibradores monoestáveis existentes na placa de som.

Estes multivibradores monoestáveis trabalham do seguinte modo:

1. Normalmente o capacitor $C 1$ está carregado $(5 \mathrm{~V})$ e a saída do multivibrador encontra-se em nível lógico alto (1).

2. Este valor é registrado no endereço I/O 201h; então, é enviado um sinal de reset para o multivibrador. Recebendo este pulso o multivibrador descarrega o capacitor $C 1$. De imediato a saída do multivibrador passa para o estado baixo (0).

3. Em seguida o capacitor começa a carregar-se novamente devido à corrente existente em $R 1$ e na resistência presente na entrada da porta, pois há uma diferença de potencial de $5 \mathrm{~V}$ entre estes dois resistores.

4. Quando a voltagem do capacitor $C 1$ atinge um valor limite, a saída do multivibrador volta ao estado lógico alto (1) e repete-se o ciclo.

Quanto maior for o valor da resistência existente na entrada maior será o tempo necessário para o capacitor atingir a voltagem limite de mudança de estado lógico. O tempo que o multivibrador demora para atingir o estado alto após receber o sinal de "trigger" será lido e convertido para um valor numérico que varia entre zero (resistência nula) e 255(resistência infinia), que pode ser representado como o valor de resistência existente na entrada da porta. O intervalo médio entre cada leitura para as entradas analógicas é de 1 a $2 \mathrm{~ms}$.

Os estados lógicos das quatro entradas digitais existentes na porta joystick são interpretados diretamente 
pelo processador através da entrada I/O. Estas entradas estão conectadas por meio de um resistor a um potencial de $5 \mathrm{~V}$, assim, normalmente apresentam um nível alto (1). Quando ligamos uma destas entradas ao terminal "ground" (terra) esta assume o valor lógico baixo (0). O intervalo de leitura para cada entrada digital do joystick é de aproximadamente $1 \mu \mathrm{s}$. Estas entradas digitais podem ser usadas para marcação de tempo ou como contadores lógicos. Um diagrama elétrico simplificado da interface de joystick de uma placa de som típica é mostrado na figura 3. No apêndice temos alguns programas de teste para as entradas analógicas e digitais.

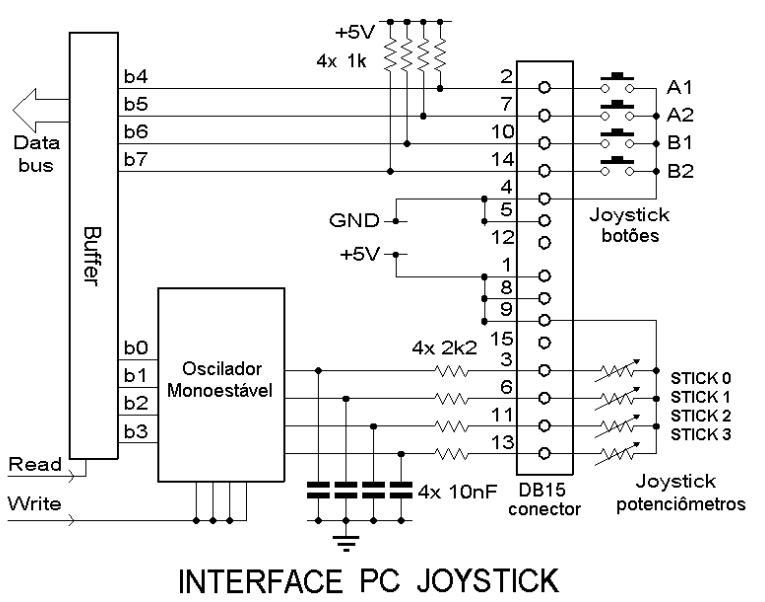

Figura 3. Circuito típico de uma interface de joystick presente na placa de som do PC. Os pinos 12 e 15 não são utilizados.

\section{II.2 Entradas e Saídas de Áudio da Placa de Som}

Quando a placa de som é utilizada para gravar um sinal analógico, como um sinal sonoro de um microfone, este sinal depois de amplificado passa por um misturador analógico (mixer), logo após é convertido num código digital pelo convesor A/D (analógico/digital) que será lido pelo processador do PC. Quando queremos transformar um sinal digital em analógico, temos o caminho inverso, a informação digital produzida pelo PC é convertida em sinal analógico pelo conversor D/A (digital/analógico) e depois é misturada e amplificada para ser transmitida (pelo alto-falante, por exemplo). A figura 4 mostra um diagrama simplificado de funcionamento das entradas e saídas de áudio da placa de som.

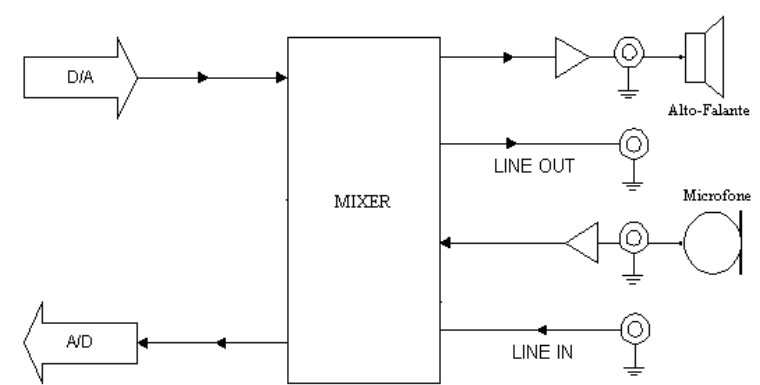

Figura 4. Resumo de funcionamento de uma interface de áudio existente na placa de som do PC.

A conversão A/D e D/A pode ser feita geralmente em 8 ou 16 bits e com uma taxa de amostragem de até $44,1 \mathrm{kHz}$. Para uma melhor resolução devemos optar pela maior quantidade de bits e maior velocidade de amostragem. Note que estes limites também dependem da velocidade do processador e capacidade de memória do microcomputador. Uma grande desvantagem que a placa de som do PC apresenta é o fato de não trabalhar com sinais de corrente contínua. Isto deve-se ao fato que as placas de som possuem capacitores ligados em série nas suas entradas e saídas de áudio. O limite de funcionamento das placas comuns está na faixa de 20 $\mathrm{Hz}$ até aproximadamente $20 \mathrm{kHz}$. Na figura 5 temos a representação das entradas e saídas de uma típica placa de som e também os seus principais módulos.

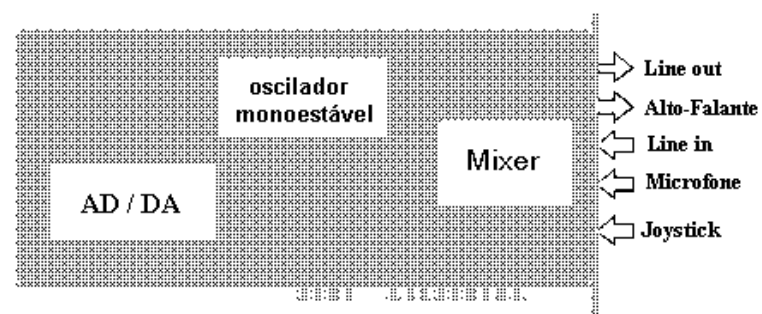

Figura 5. Uma placa típica de som e seus conectores e módulos principais.

\section{Um Exemplo de Aquisição de Dados Através da Porta}

A entrada de joystick pode ser usada diretamente na aquisição de dados. Podemos utilizar as quatro entradas digitais através de sensores ópticos (LDR(resistor cujo valor dependente da intensidade de luz), Fototransistor, etc.) ou magnéticos ("reed-switch", por exemplo) para determinação de intervalos de tempo entre eventos numa experiência. Também podemos utilizar as entradas analógicas adaptando sensores cuja resistência seja variável, como potenciômetros, LDR, PTC(resistor com variação positiva em função da temperatura) e NTC(resistor com variação negativa em função da temperatura), para a determinação da posição, intensidade luminosa e temperatura, respectivamente. Como todas as entradas podem ser utilizadas, 
até 8 grandezas físicas podem ser medidas simultaneamente.

Como exemplo de aquisição de dados via porta joystick, vamos empregar um potenciômetro na entrada analógica para medir posições angulares de um pêndulo físico. Um experimento semelhante está descrito nas referências [4] e [11], onde foi utilizada uma interface em comunicação paralela.

Um diagrama da montagem experimental é apresentado na figura 6 . O potenciômetro está fixo no suporte, que é preso na mesa de "massa infinita". O extremo superior da haste do pêndulo é preso ao eixo de rotação do potenciômetro. Quando varia a posição angular do pêndulo, o eixo gira, provocando uma variação na resistência do potenciômetro. Desta forma temos um sensor que converte uma medida de ângulo num valor de resistência. Os terminais deste potenciômetro estão ligados diretamente nos pinos 1 e 3 da entrada analógica ${ }^{2}$. O programa escrito em linguagem QBASIC para a leitura e registro do valor de resistência do potenciômetro em função do tempo é apresentado no apêndice ${ }^{3}$. O número total de medidas tomadas é o único dado de entrada do programa computacional. O arquivo de dados gerados (dados.dat) contém tão somente duas colunas: uma contendo o instante de tomada da medida e a outra contendo os valores medidos para a resistência. A partir deste arquivo de dados pode-se construir um gráfico utilizando qualquer aplicativo que cumpra esta função. Aqui utilizamos o programa Mathematica.

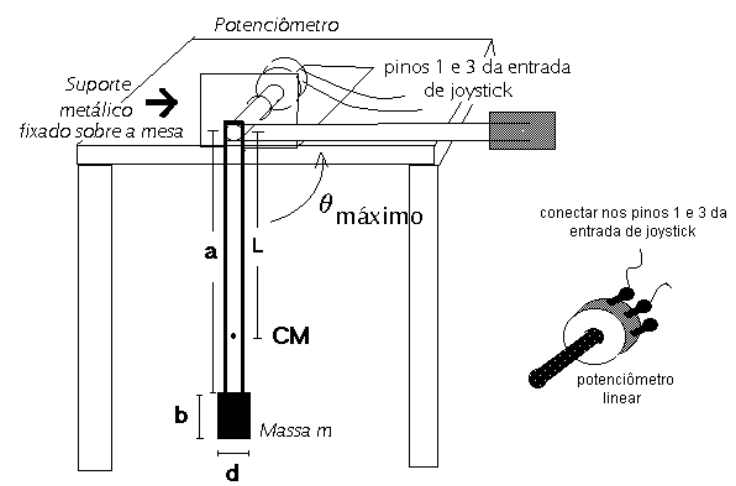

Figura 6. Diagrama do experimento.

No presente exemplo utilizamos um potenciômetro linear de $100 \mathrm{k} \Omega$, porém potenciômetros de valores entre $47 \mathrm{k} \Omega$ e $1 \mathrm{M} \Omega$ são aceitáveis. A linearidade do potenciômetro foi testada medindo com um multiteste o valor da resistência nos seus terminais para diferentes posições angulares do pêndulo. Verificamos que o desvio é inferior a $2 \%$. É importante que o potenciômetro seja linear para que a correspondência entre a medida da resistência e a posição angular seja imediata. Do contrário, seria necessário inicialmente determinar a relação entre estas duas grandezas e, então, fazer a correspondência entre os valores coletados para a resistência e a posição angular via software.

A descrição teórica deste experimento é simples, visto tratar-se de um pêndulo físico. Pela versão rotacional da segunda lei de Newton, temos:

$$
\tau_{0}=I_{0} \alpha
$$

sendo $\tau_{0}$ o módulo do torque restaurador, $I_{0}$ o momento de inércia em relação ao eixo de rotação do potenciômetro e $\alpha$ o módulo da aceleração angular do pêndulo.

O módulo do torque restaurador é dado por $M g L \operatorname{sen}(\theta)$, onde $L$ é a distância do eixo ao centro de massa do sistema e $M=M_{h}+m$ é a massa total do pêndulo, sendo $M_{h}$ a massa da haste e $m$ a massa suspensa. $\theta$ é o ângulo com a direção vertical. Então, desprezando a resistência do ar e do atrito no potenciômetro, temos:

$$
I_{0} \frac{d^{2} \theta}{d t^{2}}=-M g L \operatorname{sen} \theta
$$

Para pequenos ângulos $\operatorname{sen} \theta \simeq \theta$, de modo que

$$
\frac{d^{2} \theta}{d t^{2}}+\frac{M g L}{I_{0}} \theta=0 .
$$

Esta é a equação diferencial que descreve o movimento harmônico simples do pêndulo para pequenas amplitudes. É fácil mostrar que a solução desta equação diferencial é dada por

$$
\theta=\theta_{\max .} \operatorname{sen}(\omega t+\delta)
$$

onde a freqüência angular $\omega$ é dada por

$$
\omega^{2}=\frac{M g L}{I_{0}}
$$

Assim, o período $T$ é

$$
T=\frac{2 \pi}{\omega}=2 \pi \sqrt{\frac{I_{0}}{M g L}} .
$$

O momento de inércia $I_{0}$ deste pêndulo pode ser calculado de

$$
I_{0}=\left(\frac{1}{3} M_{h} a^{2}\right)+m\left[\frac{b^{2}+d^{2}}{12}+\left(a+\frac{b}{2}\right)^{2}\right] .
$$

Nesta equação o primeiro termo corresponde ao momento de inércia da haste em relação ao eixo que passa

\footnotetext{
${ }^{2}$ Outros pares de pinos poderiam ter sido selecionados.

${ }^{3} \mathrm{O}$ apêndice também inclui outros programas que escrevemos em linguagem QBASIC e C para a leitura e registro de dados nas entradas paralelas e digitais do joystick.
} 
na sua extremidade, o segundo termo representa o momento de inércia da massa suspensa em torno do seu centro de massa e o último termo provém do teorema dos eixos paralelos para determinação do momento de inércia da massa suspensa em torno do eixo do potenciômetro. Os parâmetros geométricos $a, b$ e $d$ estão indicados na figura 6 .

Usando os dados apropriados para o pêndulo físico em uso, obtemos: $I_{0}=0,247 \mathrm{~kg} \mathrm{~m} \mathrm{~m}^{2}$. O período é, então, $T=1,850 \mathrm{~s}$, onde usou-se para $g$ o valor local da aceleração da gravidade, $g=9,79 \mathrm{~m} / \mathrm{s}^{2}$.

$\mathrm{Na}$ figura 7 apresentamos resultados típicos para um experimento em que o pêndulo foi solto do repouso da posição inicial de $5^{0}$. Os pontos experimentais foram normalizados de modo que a amplitude máxima é 1 . A curva corresponde à Eq. 4 , onde $\theta_{\text {max }}=1$ e $\delta=0$. A freqüência angular $\omega$ foi ajustada com o programa estatístico 2DCurve, tendo-se obtido $\omega=3,382, \mathrm{rad} / \mathrm{s}$ com uma correlação de 0,96. Assim, o período extraído dos dados é $T=1,857$, s. O pequeno desvio entre o período calculado teoricamente e o obtido experimentalmente revela que o sistema de aquisição de dados através da porta de joystick empregado nesta experência possui uma satisfatória precisão.

Ainda há outros estudos interessantes que podem ser feitos com este sistema. Pode-se investigar efeitos causados por forças dissipativas, principalmente pelo atrito seco presente no eixo de rotação do potenciômetro e o atrito viscoso que pode ser ampliado fixando-se uma placa retangular rígida à massa suspensa no pêndulo físico. Ao leitor interessado sugerimos a referência [4], onde é discutido em detalhe este experimento e são apresentados resultados obtidos experimentalmente com uma interface em comunicação paralela. Resultados semelhantes são obtidos com nosso sistema de aquisição de dados via porta joystick.

Outra situação interessante que pode ser explorada com a presente montagem, é o movimento do pêndulo para ângulos quaisquer; em particular, o período do movimento em função da amplitude. Em aulas experimentais tradicionais, costuma-se limitar o estudo do movimento do pêndulo a pequenos ângulos, para os quais é feita a aproximação $\operatorname{sen}(\theta) \simeq \theta$ e a equação do movimento admite uma solução analítica dada pela Eq. 4. Visto não haver solução analítica em forma fechada para um ângulo qualquer, limita-se o estudo a pequenos ângulos. Neste tipo de experimento o microcomputador torna-se um instrumento útil no laboratório não somente na coleta de dados, mas na sua interpretação. Pode-se utilizá-lo para rapidamente resolver a Eq. 2, usando-se programas de computação algébrica, como o Mathematica, Maple e Matlab, e ampliar-se o estudo do movimento para ângulos quaisquer. Num futuro trabalho abordaremos este interessante tópico.

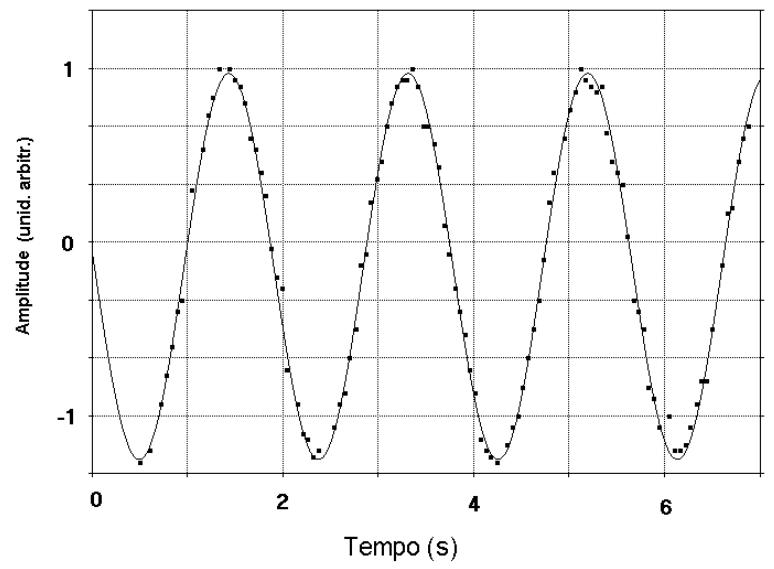

Figura 7. Gráfico dos pontos experimentais para oscilações com amplitude máxima de $5^{0}$. A curva corresponde à solução teórica descrita no texto.

\section{A Placa de Som Substi- tuindo Instrumentos de Me- didas}

Existem vários softwares que usam as entradas e saídas de áudio da placa de som para simular instrumentos de medida. Estes softwares estão disponíveis na Internet. Apresentaremos a seguir diversos softwares que já testamos em laboratório e apresentaram um bom desempenho. Todos eles são freeware.

\section{IV.1 Freqüencímetro Digital}

A placa de som do PC pode ser usada como um eficiente freqüencímetro digital para experiências no laboratório de física. A faixa de freqüência permitida para uso está entre $20 \mathrm{~Hz}$ até pouco mais de $15 \mathrm{kHz}$. Sendo satisfatória para experiências didáticas para as quais usualmente se requer a faixa de $20 \mathrm{~Hz}$ a $10 \mathrm{kHz}$. Utilizamos o conector de microfone da placa de som como entrada de sinal. Há vários softwares que podem ser utilizados, sugerimos o Frequency Counter 1.01 [14].

\section{IV.2 Gerador de Sinais}

Outra possibilidade de uso da placa de som do PC é como gerador de sinais. Atualmente existe disponível na Internet uma variedade de softwares que simulam no microcomputador este instrumento. Certos programas podem gerar na saída da placa de som várias formas de onda, como: senoidal; retangular; dente de serra; entre outras. Outros softwares vão além e possibilitam outros recursos que não são encontrados em geradores de sinais convencionais. O TTG, Test Tone Generator [15], permite gerar um sinal que pode variar a freqüência entre um minímo e um máximo num intervalo de tempo determinado (sweep function). Por exemplo, podemos utilizar este recurso para gerar um sinal sonoro entre 
$20 \mathrm{~Hz}$ e $20 \mathrm{kHz}$ em alguns milisegundos, para determinar a curva de ressonância de um objeto, analisando a absorção deste sinal gerado com o auxílio de um analisador de espectro.

$\mathrm{O}$ sinal gerado pelo $\mathrm{PC}$ é retirado no conector de alto-falante da placa de som. Devemos observar que a impedância de saída será de 4 a $16 \Omega$, dependendo da placa utilizada e a potência máxima disponível é da ordem de 2 a 3 watts.

\section{IV.3 Osciloscópio e Analisador de Espectro Di- gital}

Um dos instrumentos de medida e análise mais desejado no laboratório didático é sem dúvida o osciloscópio digital. Este versátil instrumento pode ser utilizado em inúmeras experiências. Certamente este é também um dos instrumentos de maior custo em qualquer laboratório didático de física. Como os demais instrumentos aqui expostos, os osciloscópios digitais baseados na placa de som do PC estão limitados à operação em baixa freqüência, aproximadamente no limite da faixa de áudio ( $\leq 20 \mathrm{kHz}$ ). Uma vantagem obtida na utilização destes instrumentos digitais é a possibilidade de uso da função de memória para armazenar uma imagem obtida no monitor do microcomputador. Esta imagem pode ser salva em um arquivo de imagem e posteriormente ser colocada diretamente no relatório sobre a experiência desenvolvida pelos alunos. Existem vários softwares que cumprem muito bem esta função. Citamos como excelente alternativa o Oscilloscope and Spectrum Analyzer [16]. Este aplicativo possibilita vários recursos como: duplo traço, modo XY (Lissajous) e permite exportação de dados para análise posterior na forma de imagem ou texto. Além destes recursos, ele possui a função de analisador de espectro digital em tempo real.

Existem outros aplicativos exclusivos para a análise de espectro. Alguns monitoram em tempo real o espectro do sinal analisado, isto é, aplicam uma rotina de FFT (Transformada Rápida de Fourier) que possibilita obter informações valiosas a respeito do sinal analisado. Dois ótimos softwares que podem ser utilizados para a análise espectral são o Spectrogram [17] e o FFT [18]. O primeiro aplicativo apresenta o sinal na forma de gráfico freqüência versus tempo. Este recurso pode ser usado por exemplo para estudar o efeito Doppler. Na figura 8, temos uma análise espectral obtida pelo Spectrogram, correspondente ao sinal sonoro originado por um avião a baixa altitude, podendo-se notar claramente o efeito Doppler. O arquivo em formato WAV deste sinal pode ser encontrado em [17].

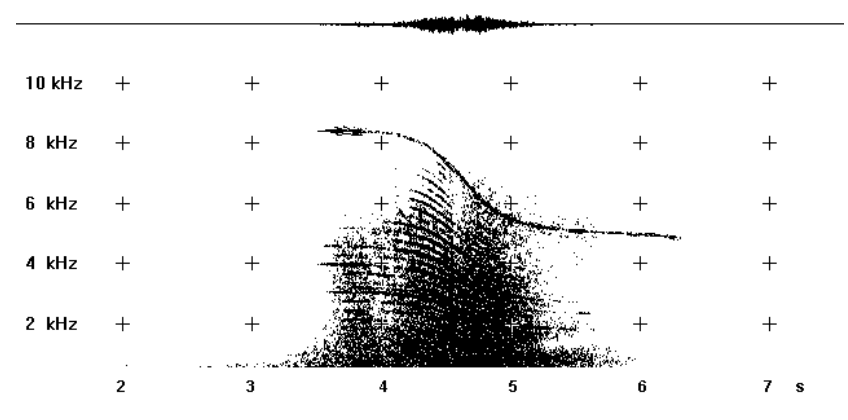

Figura 8. Imagem obtida pelo Spectrogram. Observamos o sinal sonoro emitido por um avião voando a baixa altitude. A escala horizontal é dada em segundos e a vertical em $\mathrm{kHz}$.

Podemos ainda utilizar alguns softwares de edição de áudio, como por exemplo o Cool Edit, da Syntrillium Software [19]. Este programa pode ser usado no lugar do gravador de som que acompanha o sistema operacional MICROSOFT WINDOWS, pois permite um maior controle sobre o sinal a ser armazenado e propicia outros recursos, como conversão do sinal armazenado para vários formatos (WAV, $\mathrm{AU}$, etc).

\section{Conclusão}

Neste trabalho mostramos como utilizar a placa de som do microcomputador na aquisição de dados, substituindo vários instrumentos de medidas considerados indispensáveis num bom laboratório de ensino de física. Acreditamos que esta alternativa é preferível à construção de circuitos eletrônicos que venham a desempenhar a função de conversores analógicos-digitais, bem como à utilização de interfaces comerciais para tal fim, quer pela questão do custo econômico, quer pela praticidade.

Acreditamos ter contribuído no sentido de dar ao professor ferramentas para adaptar as atividades do laboratório didático à Física Contemporânea e ao mundo moderno que está em constante mudança, para mostrar a Física como uma Ciência, não somente inserida neste contexto, mas como um importante agente destas transformações. Nossos professores precisam estar conscientes da importância de inserir novas tecnologias no laboratório didático e precisam ser auxiliados nesta tarefa. Como mostramos neste artigo, não se faz necessário conhecimento profundo por parte do professor quer de uma linguagem de programação quer de "hardware", basta ter a mente aberta às novas tecnologias, pois o ensino da física para a cidadania necessariamente obriga o professor a repensar o seu papel na sala de aula e no laboratório.

\section{Agradecimento}

À professora Eliane A. Veit pelo auxílio na correção do manuscrito e pelo aprendizado proporcionado durante a produção deste trabalho. 


\section{Apêndice}

Colocamos neste apêndice pequenos programas em linguagem QBASIC e C usados para coletar dados através da porta joystick. Mostramos nestes programas a utilização das entradas digitais e analógicas disponíveis na porta joystick. O primeiro programa lê o valor de resistência do potenciômetro conectado nos pinos 1 e 3 do conector DB15 (entrada stick(0)) e gravao juntamente com o tempo do relógio do computador num arquivo chamado de dados.dat. Neste programa, que foi utilizado no experimento com o pêndulo, utilizamos apenas a entrada analógica stick(0). As outras entradas na linguagem QBASIC são acessíveis usando os comandos stick(1)(pinos 6 e 8), $\operatorname{stick}(2)(\operatorname{pinos} 11$ e 9) e $\operatorname{stick}(3)(\operatorname{pinos} 13$ e 9$)$.

\section{CLS}

SCREEN 12: COLOR 7

INPUT "Numero de medidas: ", $\mathrm{k}$

OPEN "c: \dados.dat" FOR OUTPUT AS \#1

$\mathrm{TT}=\mathrm{TIMER}$

FOR $i=1 \mathrm{TO} k$

$r 1=\operatorname{STICK}(0)$

$\mathrm{T}=\mathrm{TIMER}-\mathrm{TT}$

PRINT \#1, T, r1

NEXT i

CLOSE \#1

Abaixo descrevemos outro programa, muito semelhante ao primeiro, escrito em linguagem $\mathrm{C}$, que pode ser usado para verificar o funcionamento das quatro entradas analógicas da porta joystick ou servir como base para outro aplicativo.

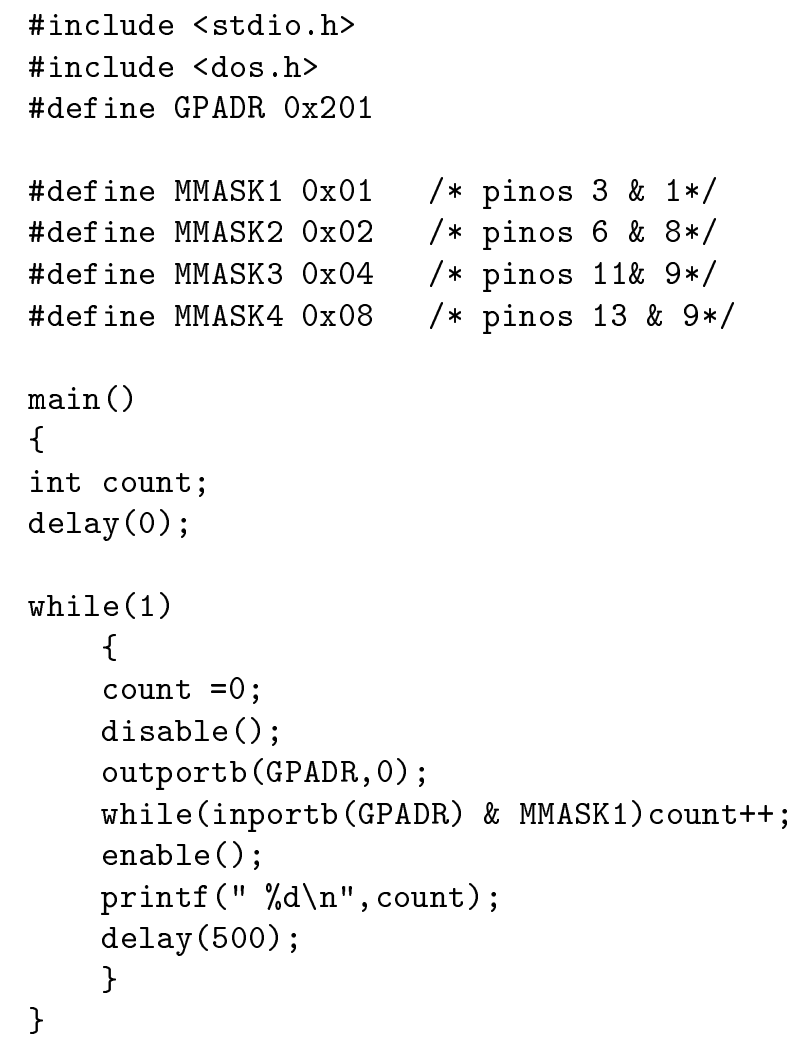

A seguir temos dois pequenos programas que utilizam as entradas digitais na porta joystick. O primeiro utiliza a função STRIG da linguagem QBASIC para monitorar o estado lógico das entradas digitais. Em seguida temos um programa semelhante em linguagem $\mathrm{C}$. Ambos podem ser usados como referência para acesso às entradas digitais da porta joystick.

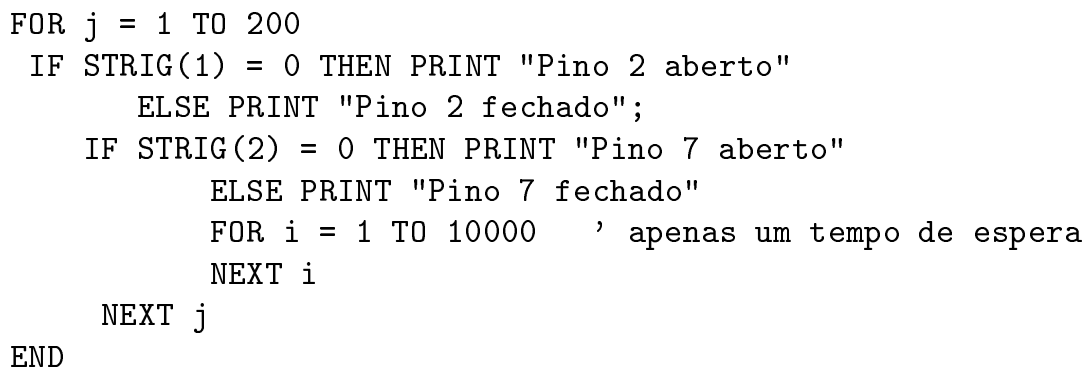

O programa a seguir está escrito em linguagem $\mathrm{C}$ e monitora as entradas digitais da porta joystick.

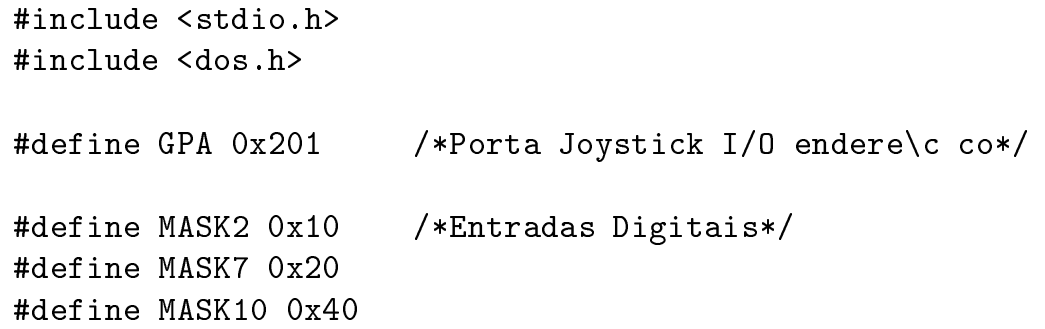




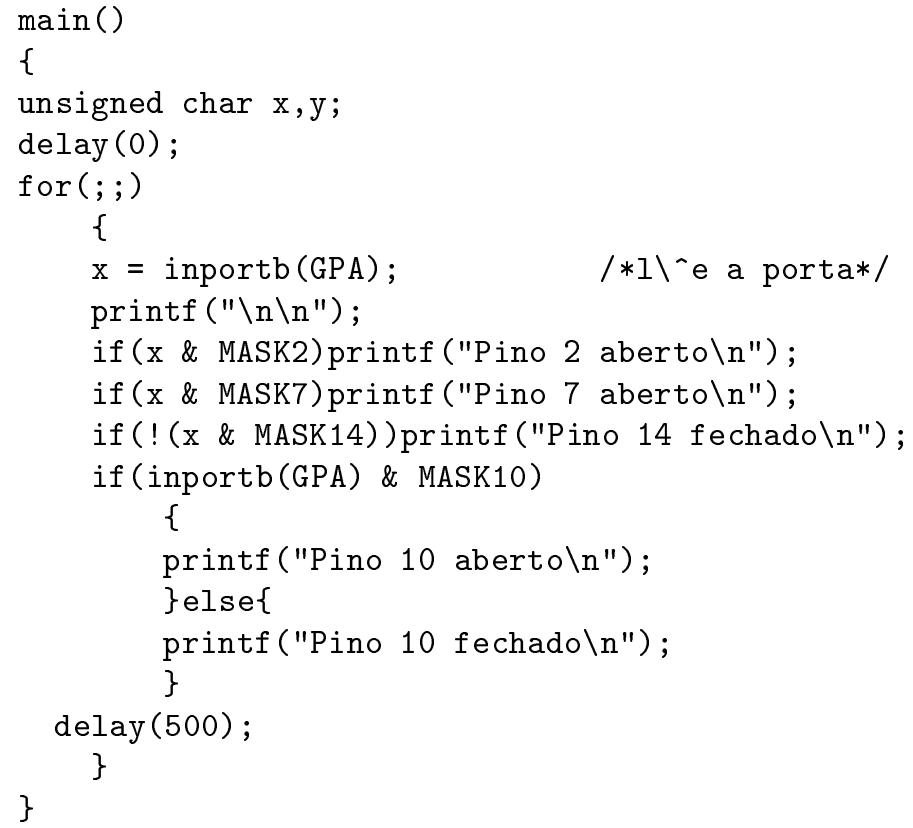

\section{References}

[1] W. M. Gonçalves, A. F. Heinrich e J. C. Sartorelli, Rev. Ens. Fís., 13, 63 (1991).

[2] D. F. de Souza, J. Sartori, T. Catunda e L. Nunes, Rev. Bras. Ens. Fís., 17, 196 (1995).

[3] R. V. Ribas, A. F. de Souza e N. Santos, Rev. Bras. Ens. Fís., 20, 293 (1998).

[4] D. F. de Souza, J.Sartori, M. J. V. Bell e L. A. O. Nunes, Rev. Bras. Ens. Fís. 20, 413 (1998).

[5] M. A. Cavalcante e C. R. C. Tavolaro, Rev. Bras. Ens. Fís. 22, 247 (2000)

[6] M.A. Cavalcante e C.R.C. Tavolaro, Rev. Bras. Fis. 22, 421 (2000)

[7] M. A. Cavalcante, Rev. Bras. Ens. Fis. 21, 550 (1999).

[8] R. O. Ocaya, Phys. Educ. 35, 267 (2000)

[9] R. Wisman e K. Forinash, Am. J. Phys. 59, 187 (1991).

[10] A. Henríquez, P. Gil e M. Alvares, Am. J. Phys. 62, 568 (1994)

[11] R. C. Nicklin e J. B. Rafert, Am. J. Phys. 52, 632 (1984).

[12] http://www.pasco.com. Vários sistemas de aquisição de dados para uso no laboratório de física.

[13] http://www.picotech.com. Softwares e sistemas de aquisição de dados.

[14] http://www.muenster.de/ welp/sb.html. Excelente site com vários softwares que utilizam a placa de som do PC.

[15] http://www.esser.u-net.com. Software que simula um gerador de funções com várias formas de onda.

[16] http://polly.phys.msu.su/ zeld/oscill.html Osciloscópio digital e analisador de espectro, utilizando a placa de som do PC.

[17] http://www.monumental.com/rshorne/gram.html. Software para análise espectral.

[18] http://www.geocities.com/capecanaveral/lab/2773. Analisador de espectro. Não permite análise em tempo real.

[19] http://www.syntrillium.com. Editor de áudio com vários recursos. 